\title{
The Role of Identifying the Lexical Relations among Target Vocabulary Words through Blended Learning on EFL Students' Mastery in Using Target Vocabulary
}

\section{Sahar Hussein Aboud Alameh}

PhD Student, Department of English, Faculty of Human Sciences, Lebanese International University (Saida Campus), Lebanon

Doi:10.19044/esj.2018.v14n35p358 URL:http://dx.doi.org/10.19044/esj.2018.v14n35p358

\begin{abstract}
This paper examines the effect of identifying the lexical relations among target vocabulary items through a blended learning approach on improving EFL students' mastery in using target vocabulary. At first, this study aims at showing how the difficulties in using lexical units from a semantic perspective result in the production of erroneous sentences and consequently affect the collaborative process of communication. The current study will use an experimental approach, a true experiment, to analyze the data and verify the results of using various online and offline instruction and tasks with the goal of improving students' lexical awareness and development to master the target vocabulary. A total of 60 students sharing a similar social and educational background were randomly assigned to the experiment. The experimental group studied the target vocabulary items through blended learning strategies while the control group learned the same target vocabulary items through traditional way of teaching. After the traditional in class instruction period, a paper-based vocabulary test was administered to both groups of students; however, the experimental group which was made up of 30 students from the same section was taught the same target vocabulary items for a period of 4 weeks through blending task-based DDL instruction and in class instruction. The results of the study indicate that EFL students at LIU (Lebanese International University) make substitutional (synonym) lexical errors frequently; however, the results of the experimental group after receiving the blended pedagogic intervention with a systematic lexical and communicative approach surpassed their results before receiving the treatment. That is why students in the posttest showed a broader ability to produce a well-structured written text and comprehend a reading text as well.
\end{abstract}


Keywords: Lexical relations, blended learning, target vocabulary, DDL (Data Driven Learning) teaching methods, ENG 151(Advanced Writing Skills)

\section{Introduction}

Vocabulary plays a significant role in foreign language learning. Zahedi and Abdi (2012) asserted that "words are the building blocks of a language since they label objects, actions, ideas without which people cannot convey the intended meaning." (p.273). Many researchers back up the viewpoint that providing vocabulary instruction not only improves students' reading comprehension and writing quality but also boosts their listening vocabulary and their speaking vocabulary. Teaching students to develop vocabulary means providing explicit instruction on important words from the text and teaching students strategies to help them learn word meanings independently. Loftus \& Coyn (2013) contend that it is demanding for both oral and written vocabulary augmentation to develop as students get older to enable them to comprehend increasingly more complex grade-level text. There are a variety of approaches to teach vocabulary, but mastery of vocabulary can only be obtained with the teaching strategies that respect various learning styles. Many researchers like Khazaei and Dastjerdi (2011) have demonstrated that different technology-based instructional materials are beneficial for effective verbal and written communication. Therefore, many higher education institutions today are using blended learning as a supplementary means to develop students' vocabulary knowledge. Blended learning approach in teaching foreign language has become a matter of considerable interest to language teachers all over the world. As opposed to pure e-learning which refers to using only electronic media to learn, blended learning supplement traditional face-to-face teaching and learning environment with different kinds of technology-based instruction. So, blended learning is one of the various approaches which combine the positive attributes of online and face-to-face instruction (Hinkelman \& Gruba, 2012). Without some knowledge of vocabulary, neither language fabrication nor language understanding would be possible. Thus the augmentation of vocabulary knowledge is one of the essential prerequisites for language acquisition and this growth of vocabulary knowledge can only be possible when teachers employ effective vocabulary teaching and learning strategies that depend heavily on identifying the different lexical relations among the target vocabulary items. Therefore, it is hoped that the present study investigates the efficacy of identifying the lexical relations among target vocabulary items through blending task-based DDL instruction and in class instruction in order to enhance EFL students' target vocabulary acquirement. This study would be helpful for language teachers and researchers in giving insights in terms of integrating DDL into current language courses and for corpus software designers in considering the opinions of language learners. 


\section{Statement of the Problem}

Many LIU students in southern campuses are able to understand the English language, but most face problems effectively communicating and developing their ideas. The major problem is the lack of adequate stock of English vocabulary. Many ENG 151(Advanced Writing Skills Course) instructors at LIU Saida Campus have confirmed the important role vocabulary knowledge plays in improving the students' reading comprehension and essay writing, and therefore in their success in ENG 151 course. Also, having limited vocabulary knowledge, students are not able to express and communicate well. For this reason, the main purpose of this study is to generally explore students' vocabulary learning strategies and to investigate which effective vocabulary learning strategies are used by high and low proficient in order to further provide students with effective vocabulary learning strategies.

\section{Literature Review}

According to Lundahl (2012), the approach towards teaching vocabulary language that is still heavily influenced by traditions where words are separated from context is now something that is considered outdated according to the current body of literature used in our education as teachers. Lightbown and Spada (2013) claim that a reason for this could be that the field of vocabulary acquisition has generally been a neglected field of research during the 1970 s to the mid-1990s. They also believe that the field of vocabulary acquisition has now "become one of the most active areas in second language acquisition research" (Lightbown \& Spada, 2013, p. 60). Ma \& Lin (2015) designed a research study to investigate the overall and relative contribution of four subcomponents of vocabulary knowledge to reading comprehension. The four vocabulary subcomponents were vocabulary size, word association knowledge, collocation knowledge, and morphological knowledge. Among the three subcomponents of the depth of vocabulary knowledge, collocation knowledge explained the most proportion of variance $(5.6 \%)$ in contributing to performance on reading comprehension.

Most of the researchers who have studied blended learning approach and its place in enhancing vocabulary knowledge listed a great number of positive effects. Zhang, Song and Burston (2011) examined the effectiveness of vocabulary learning via mobile phones and compared two groups of students at a Chinese university. While one group of students studied a selected list of vocabulary via text messages, the other group of students worked on the same list through paper material. When students' test results were compared, their findings revealed that "students can learn vocabulary more effectively shortterm via mobile phones than with paper material". Similarly, Khazaei \& Dastjerdi (2011) made a comparative study on the impact of traditional and 
blended teaching on EFL learners' vocabulary acquisition to explore the application of SMS to the blended method of teaching L2 vocabulary. The results revealed that the students who received the learning content through blended teaching approach had better test results than the group of students who received the learning content in the traditional way.

Exploring the impact of blended learning strategies in identifying the various lexical relations that exist among target vocabulary items might reveal individual differences in vocabulary learning among students and encourage EFL teachers to design instructional materials in accordance with their students' preferences. The present study, therefore, aims to identify not only students' perceptions of blended learning and identification but also the impact of this strategy on students' mastery and usage of vocabulary. With respect to this aim, the present study raises the following research question:

The research question that guided the study is:

1. To what extent does EFL students' awareness of the lexical relations among words through blended learning approach affect positively on EFL learners' mastery of vocabulary usage?

\section{Methodology}

The current study will use an experimental approach to analyze the data and verify the results of using various online and offline instruction and tasks with the goal of improving students' lexical awareness and development to master the target vocabulary.

\section{Participants}

The participants of this study will match on common measures including gender, age, years of language study, and language(s) spoken at the home. A total of 60 students (both male and female), whose age range is 18-21 years old and mother language spoken at home is not English (L1 is Arabic), will serve as participants for this study. In the academic year 2017-2018, undergraduate EFL learners were selected from a Lebanese university in Southern Lebanon (private). Most of the learners have studied EFL since kindergarten (so, for about 17 years), as per Lebanese curriculum requirements. Since all the learners had taken a placement test before attending the university classes, they were regarded homogenous in terms of proficiency level. As first- or second-semester EFL students, the students learn EFL a total of 12 hours per month (4x3) based on the number of instruction hours seen in the university system. The study took place at LIU (Saida Campus) in Advanced English and Writing Skills (ENG 151) class where awareness and development of lexical relations is one of the core requirements in their syllabus in the academic year 2017/2018. The study was supervised by the researcher herself on the experimental group and the control group. A total of 
60 remedial students enrolling in ENG 151 course at LIU (Lebanese International University) and sharing a similar social and educational background were assigned to the experiment. The experimental group studied the target vocabulary items through blended learning strategies while the control group learned the same target vocabulary items through traditional way of teaching. After the traditional in class instruction period, a paper-based vocabulary test was administered to both groups of students; however, the experimental group which was made up of 30 students from the same section was taught the same target vocabulary items for a period of 4 weeks through blending task-based DDL instruction and in class instruction which was followed by the posttest to assess their target vocabulary acquisition.

\section{Data Collection:}

In this study the triangulation method is employed. Current best research practice to Mackey \& Gass (2005) is to use multiple measurements to triangulate results from more than one approach in order to achieve sound findings (p. 181). Triangulation entails the use of multiple, independent methods of obtaining data in a single investigation in order to arrive at the same research findings: questionnaires as surveys, pre-tests, post-tests, observation, interviews, accounts, rating scales, anecdotes, portfolios, and correction rubric (Davies, 2004, p. 141). Multiple research techniques and multiple sources of data explore the issues from all feasible perspectives. Employment of triangulation technique enhances credibility, transferability, conformability and dependability of the research (Mackey, \& Gass, 2005 p. 149; Duff, 2007, p.143), which are crucial features to any type of research. Here methodological triangulation involves: using multiple data-gathering procedures, such as: surveys, interviews with students, observations, and pretest and posttest.

Before describing data collection instruments we will find quantitative and qualitative data collection methods.

\subsection{Quantitative Data collection}

Quantitative research advocates use of quantitative data collection, seeks facts or causes of social phenomena regardless to the subjective states of the individuals employing controlled measurements. It is extracted from the prospective data of the 'outsider' objectively. Moreover, it is "verificationoriented, confirmatory, reductionist, inferential and hypothetical-deductive, outcome-oriented, reliable, hard and replicable data generalizable good for multiple case studies and assumes a stable reality" (Nunan, 2008, p. 5). Quantification of data is carried through measurements, frequencies, scores, and ratings (Mackey, A. \& Gass, S., 2005, p. 162). Those measures, turn into numbers and statistics on condition that validity, reliability and objectivity are 
sustained (Brown and Rodgers 2002, pp. 248-9). Quantitative data in this experimental research will be collected through survey questionnaires, the participants' scores in the English Pre- Post-tests over the scholastic year 20172018.

The Questionnaires of this study will be standard, clear and exhaustive; and ask for empirical data as advised by Cohen et al. (2005, p. 247). The purpose of collecting empirical data will help to operationalize the measurement constructs and present a uniform stimulus to respondents in order to compare their responses as Martin (2006, p.2) has said.

\subsection{Qualitative Data Collection}

Qualitative research is mainly concerned with the provision of careful and detailed descriptions as opposed to the quantification of data through measurements, frequencies, scores, and ratings (Mackey \& Gass, 2005, p. 162). Qualitative research is process-oriented, naturalistic, uncontrolled observation, subjective, close to data from the perspective of the 'insider', exploratory descriptive, inductive, its validity is described as real, rich, deep data and assumes a dynamic reality (Nunan, 2008, p. 5).

In this study, qualitative data will be obtained through board observations and the samples of student answers to the survey questionnaires.

\section{Instruments of Data Collection}

\subsection{Pretest and Posttest Questionnaires:}

Usually, an educational experimental research to Mackey \& Gass (2005) determines whether a program or intervention had the intended causal effect on its participants. The three key components of this research are: (1) Pre-test (to ensure comparability of the participant groups prior to their treatment) and post-test (to measure the effects of treatment) (2) experimental and control groups (to investigate research questions) and (3) random assignment of study participants (pp.146-149).

In his research into the acquisition of vocabulary, Schmitt (2010) necessitates determining what vocabulary knowledge exists at a point in time (usually before an experimental treatment) and then establishing what the state of knowledge is at a later point. To him this is often explored with some form of Test 1/pre-test (T1) -treatment-Test 2/post-test (T2) research design. The need for the $\mathrm{T} 1$ is obvious, because if pre-existing knowledge is not established at the beginning, it is impossible to know whether T2 knowledge is new acquisition or simply knowledge that was in place before the study began (p.179).

Survey questionnaire (see Appendix A, part II) will also be used for ease of sampling, to assess the students' attitudes towards the effectiveness of the blended learning approach in identifying the various lexical relations among 
the target vocabulary. The questionnaire consisted of 11 items which were rated on a 5-point Likert scale (1=strongly disagree, $5=$ strongly agree). The majority of the items were designed by the researchers according to the related literature and the nature of the study. According to the factor analysis, the questionnaire was divided into two categories: Learners' attitudes towards the effectiveness of lexical awareness in students' mastery of target vocabulary via online websites and the efficiency of blended learning approach in vocabulary learning.

\subsection{Pretest Knowledge Rating Checklist:}

To Mackey and Gass (2005), educational experimental research determines whether a program or intervention had the intended causal effect on participants. The three key components of this research are: (1) Pre-test (used to ensure comparability of participant groups prior to treatment) and post-test (used to measure the effects of treatment); (2) experimental and control groups (used to investigate research questions); and (3) random assignment of study participants (pp. 146-149).

To select the appropriate words for this study, a checklist of 30 words was prepared. The words were selected from theme 1 Remembering and Forgetting. In selecting the words two criteria were considered: 1. All the words were the basic vocabulary for developing an essay relevant to theme one. 2. The words presented in this study had different parts of speech.3. The meanings of some words are very similar. In order to ensure that the selected words were unknown to the participants, the checklist was handed to the participants in this study. The learners had to write the meaning of the words they knew. The familiar words were excluded. Hence, a list was developed including new words about which the learners did not have any previous knowledge or mastery in using them.

\subsubsection{Knowledge Rating Checklist}

How much do I know about each of the following target words on the checklist to be able to use them appropriately in different situations?

\begin{tabular}{|l|l|l|l|l|}
\hline Target vocabulary item & Do not know & Have seen/ heard & Can define & Can define and use \\
\hline remember & & & & \\
\hline recall & & & & \\
\hline revise & & & & \\
\hline rehearse & & & & \\
\hline retrieve & & & & \\
\hline retain & & & & \\
\hline repeat & & & & \\
\hline recognize & & & & \\
\hline remind & & & & \\
\hline restore & & & & \\
\hline prompt & & & & \\
\hline encode & & & & \\
\hline
\end{tabular}


The results of the preceding checklist made the researcher sure that most of the students in both groups, the experimental and control group, do not either know the real meaning of each word or how to use them.

\subsection{Pretest and Posttest Vocabulary Quiz:}

\subsubsection{Recognition Exercises}

In this study, one type of recognition exercises was designed. Fill in the blank exercise which includes the twelve target vocabulary items. Following, an example is presented:

Fill in the blanks with a word from the box. Use the correct form of the word where necessary. Two extra words were added.

\begin{tabular}{|l|l|l|l|l|l|l|}
\hline revise & encode & forget & retain & remind & prompt & repeat \\
\hline rehearse & retrieve & recall & decode & restore & remember & recognize \\
\hline
\end{tabular}

In 1959, two researchers conducted an experiment into memory storage. The experiment demonstrated the value of rehearsal in storing new information. Most participants could not ------------- (a) the new information. This shows that new information does not stay in short- term memory without --------------------- (b).

\subsubsection{Production Exercises}

One type of production exercise is developed in this study where the students are expected to use as many words as possible from the previous fill in the blank exercise or their synonyms in order to write a short paragraph on memory and its role in learning.

\section{Procedure}

The major resource for ENG 151 course is a course pack that consists of Progressive Skills in English book and a workbook). The overall aim of ENG 151 Course is to instruct students in reading -writing fluency, vocabulary, writing conventions, and academic skills necessary for university level. But this study focuses on Theme I: Remembering and Forgetting and mainly the Vocabulary for the reading section that aims at building students' core vocabulary to recognize and demonstrate recognition of target vocabulary to understand a lecture or a text about memory and learning.

The main concern of this study was to investigate the effectiveness of integrating the blended teaching approach to identify the lexical relations among target word vocabulary on EFL learners' vocabulary mastery. To this end, 60 learners participated in this study. All participants will be involved from the beginning to the end of the study. Since all the learners had taken a placement test before attending the Institute classes, they were regarded homogenous in terms of proficiency level. The participants were randomly 
classified into control and experimental groups. The pre-test was applied to both groups (control and experimental groups) by the researcher in November. During the procedure, both the control and experimental groups will be exposed only to in-class traditional lectures and workbook exercises, in the first two weeks, based on the course book requirements and will be given only the meanings of the words in a handout. Then they will do a vocabulary quiz that evaluates their mastery of theme 1 target vocabulary. After running test 1 in theme 1 target vocabulary, only students in the experimental will be exposed to various websites to identify the lexical relations among the twelve target vocabulary items. The choice to use blended teaching approach is based on my literature review which shows that most recent studies identify discernible findings that support the use of blended learning and its benefits in learning a foreign language and second language (L2) vocabulary autonomously for students. That is why the freely-available contemporary corpus of English such as: www.collinsdictionary.com, www.oxforddictionary, www.lextutor.com, Web collocates, and BNC concordancers websites were used in order to help students in identifying lexical relations among the target vocabulary items. Then the researcher assigned a take- home assignment whose aim is to make students in the experimental group visit various websites to pick up the definition of each word, synonym, antonyms, collocations, and its various morphological forms. Besides they were asked to construct 5 sentences of each target vocabulary where each sentence should present the verb in a different situation, taking into consideration that each student should send this assignment in a power point form to the teacher via mail. After receiving the students' assignments, the target vocabulary items were discussed in the class where students sit in groups. Six groups were constructed. The students in each group used all the printed online handouts where each word was followed by its part of speech, a definition, synonyms, antonyms, morphological forms, and an example sentence in order to solve the in-class activities and discuss the lexical relations of each verb. Students in the experimental group were expected to write, using as many as possible the given target vocabulary, a short paragraph about forgetting and remembering. Besides, the instructor and the students read many texts that included the target vocabulary items in different situations

After two weeks of instruction and discussion, students were assigned a vocabulary quiz which represents the post-test. The quiz presented in two different exercise types was administered to the learners in the experimental group to see whether the vocabulary acquisition and retention significantly differed between the time when students depended on traditional instruction that lacked the focus on the various lexical relations among the target verbs and the other time when classroom instruction was backed up with online research and activities that reinforce students' awareness of the target words' 
lexical relations. After conducting the procedure, the vocabulary posttest was also administered to the experimental group to examine the effect of different exercise types on EFL learners' vocabulary acquisition.

\section{Data Analysis}

Data distributions were analyzed using normal Q-Q plots. Results from the quantitative variables are presented as either their means \pm standard deviation or as their medians and inter-quartile range. Differences between a series of independent or paired observations were compared using independent or paired Student's t-test (for parametric test). Test for significance was two-tailed and all analyses adopted an alpha-risk value of 0.05. All statistical analyses were performed with SPSS software (version 23.0; SPSS Inc., Chicago, IL, USA).

\section{Comparison of posttest scores between experimental and control group:}

A total of 60 students were enrolled in this study. Students' scores in control and experimental group (before and after the treatment) are detailed in Table 1 and 2 . In brief, table 1 shows the comparison of the experimental group both before and after treatment with the control group. We found out that there exists no difference between the performance of the students in the experimental group before treatment and that of the control group (46.43干14.68 vs. 51.6干16.5, $p=0.2$ ); however, there exists a difference between the results of the experimental group after treatment and those of the control group (46.43干14.68 vs. 64.2干12.4, $p<0.0001)$. This allows us to conclude that the blended instruction approach improved the scores of the students in comparison with the conventional approach.

Table 1. Results of independent sample t-test analysis for the difference between the experimental group (Before and after treatment) and control group.

\begin{tabular}{ccc}
\hline & Mean $\mp$ sd & p-value \\
\hline Control group & $46.43 \mp 14.68$ & \\
Before Treatment in & $51.6 \mp 16.5$ & 0.20 \\
experimental group & $64.2 \mp 12.4$ & $<0.0001$ \\
After Treatment in & & \\
experimental group & & \\
\hline
\end{tabular}

\section{Comparison of posttest scores in the experimental groups:}

In table 2, the mean score after treatment was greater than the mean score before treatment $(64.2 \mp 12.4$ vs. $51.6 \mp 16.5, p=0.00001)$. That means there is a statistically significant difference between the students' target vocabulary post-test and pre-test scores in the experimental group with respect to the type of the treatment. In addition, the median score $(50.5 / 100, \mathrm{IQR}$ : 37.8-65.3) before treatment was lower than the median score after treatment (65.5/100, IQR: 56.3-73.5). 
Table 2. Description of the scores before and after treatment as well as the results of Paired sample t-test analysis for the difference between the pretest and post test scores of the group

\begin{tabular}{cccc}
\hline & Before Treatment & After Treatment & p-value \\
\hline Mean $\mp \mathrm{sd}$ & $51.6 \mp 16.5$ & $64.2 \mp 12.4$ & $<0.00001$ \\
Median $(\mathrm{IQR})$ & 50.5 & 65.5 & \\
& $(\mathrm{IQR}: 37.8-65.3)$ & $(\mathrm{IQR}: 56.3-$ & \\
& & $73.5)$ & \\
\hline
\end{tabular}

Therefore, it can be concluded that after receiving a blended instruction approach which mixed between in class instructions, online vocabulary websites, and lexical relation activities, students showed significantly higher performance in the vocabulary test than when they received instructions in the conventional approach.

Figure 1: Students' answers on 11 questions according to the scale of 5 opinions (1: strongly disagree; 5 : strongly agree)

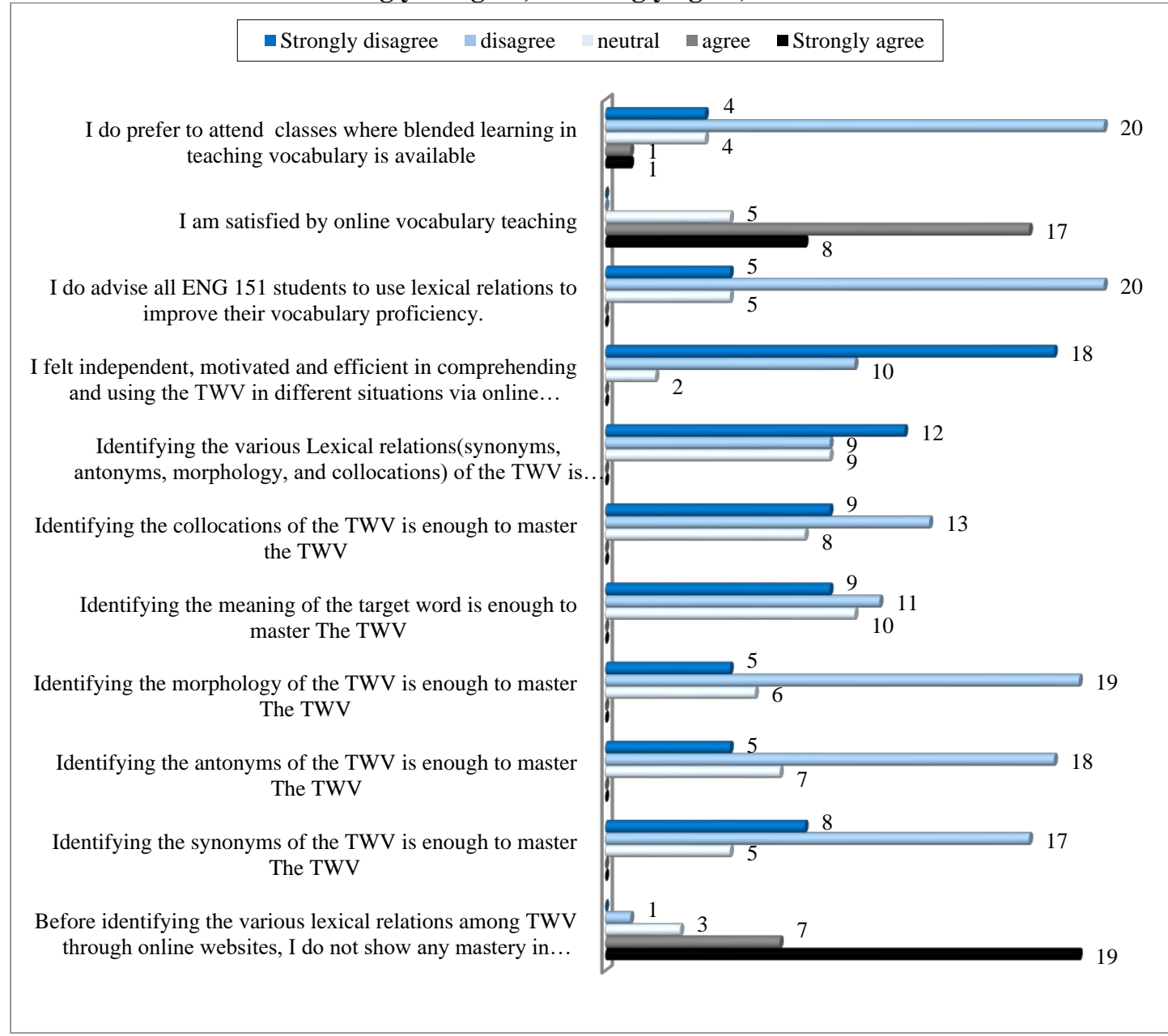


The above bar graph shows that not only most ENG 151 students agree that they benefit from the blended learning approach in acquiring the target vocabulary items, but they also advise their ENG 151 colleagues to use this approach to boost their mastery in using them.

\section{Discussion and Conclusion}

The variety of perspectives and units of analysis, which can achieve a complete understanding, requires the integration of both qualitative and quantitative methods (Balram, 2003). When used together, the two methods can offer a powerful resource to inform and illuminate strategies and practices. Therefore, the data will be analysed both quantitatively and qualitatively. To measure the students' development, the results will be first analyzed quantitatively and then will be backed up qualitatively.

At first, for quantitative analysis, the pre-test and post-test summative testing records will be numerically analysed to show and measure the mean and significant differences between the scores of the students in the experimental group before and after following instruction of English target vocabulary. Tables, figures, bar graphs and charts will be used to display the transformation. Therefore, the data which were gathered quantitatively from students' pre-tests and post-tests (which were administered respectively) show that the participants in the group were similar in terms of their vocabulary competence before the treatment. After the treatment, the post-test was administered to students in order to determine the impact of blended instruction that focused on the identifying the various lexical relations of the target vocabulary on the participants' mastery of the target verbs. In Table 1, the findings of the pos-test have demonstrated that the instruction through online activities (lexical activities and concordancing) were found to be significantly affecting students' vocabulary learning in the current study, for the median score (50.5/100, IQR: 37.8-65.3) before treatment was lower than the median score after treatment (65.5/100, IQR: 56.3-73.5). Thus, students who received instruction through online and in class activities to identify the lexical relations among target vocabulary items showed significantly higher performance in the recognition of vocabulary test to the time when they received instruction in the traditional method.

For qualitative analysis, the data collected from the post-test questionnaire will be discerned, examined, and interpreted. The aim of this kind of analysis is a complete, detailed description of the changes that will occur from the beginning of the study to its end. Such changes are related to the impact of blended instruction that focused on the identifying the various lexical relations of the target vocabulary on the participants' mastery of the target verbs. For example, questions 1, 2, 4, and 5 show that more than half of the students either agree or strongly agree that they showed better output in identifying the 
various lexical relations among target words and in using the target vocabulary proficiently and independently in various situations, after being exposed to the the treatment. Besides, in question 3, the majority of the students (75\% of the students) strongly advise other Eng 151 students to identify the lexical relation among target word vocabulary to improve their vocabulary proficiency.

Eventually, the results obtained from the qualitative and quantitative analysis are consistent with the previous researches that have asserted the positive impact of using the blended instruction approach to identify the various lexical relations among target vocabulary items on vocabulary learning over the traditional method.

\section{References}

1. Balram, Sh. (2003). Sholz, Ronald W., and Olaf Tietje. Embedded case study methods: Integrating quantitative and qualitative knowledge. Canadian Journal of Urban Research, 12, http://www.questia.com/PM.qst?a=o\&d=5006229422

2. Binkai, J. (2012). An empirical study on corpus-driven English vocabulary learning in China. English Language Teaching, 5(4), pp131.

3. Çelik, S., \& Elkatmış, M. (2013). The effect of corpus assisted language teaching on the learners' proper use of punctuation marks. Educational Sciences: Theory and Practice, 13(2), 1090-1094.

4. Gruba, P., \& Hinkelman, D. (2012). Blending technologies in second language classrooms. New York: Palgrave Macmillan.

5. Khazaei, S., Dastjerdi, H.V. (2011). An Investigation into the Impact of Traditional vs. Blended Teaching on EFL Learners' Vocabulary Acquisition: M-learning in Focus. International Journal of Humanities and Social Science, 1(15), 202-207_learning. SciVerse Science Direct, 69 (2012), 2264-2272.

6. Lightbown, M. Patsy. \& Spada, Nina. (2013). How Languages are Learned 4th edition. Oxford: Oxford University Press.

7. Loftus, S. M.,\& Coyne, M. D. (2013). Vocabulary instruction within a multi-tier approach.Reading \& Writing: Overcoming Learning Difficulties, 29(1), 4-19.

8. Lundahl, Bo. (2012). Engelsk språkdidaktik: texter, kommunikation, språkutveckling. (3., [rev.] uppl.) Lund: Studentlitteratur.

9. Lundahl, Bo. (2014). Texts, topics and tasks: teaching English in years 4-6. (1. ed.) Lund: Studentlitteratur.

10. Ma, Y., \& Lin, W. (2015). A Study on the Relationship between English Reading Comprehension and English Vocabulary Knowledge. Education Research International, 1(1), 21-15. Egypt: Hindawi Publishing Corporation. https://doi.org/10.1155/2015/20915 
11. Mackey, A. \& Gass, S. (2005). Second language research: Methodology and design. New York, NY: Routlege

12. Nunan, D. (2004). Task-Based Language Teaching. Cambridge University Press (ISBN-13: 978-0-511-66733-6)

13. Nunan, D. (2008). Research Methods In Language Learning. Cambridge University Press (ISBN: 978-0-521-42968-9)

14. Zahedi, Y. \& Abdi, M.(2012). The impact of imagery strategy on EFL learners'vocabulary

15. Zhang, H., Song, W., \& Burston, J. (2011). Reexamining the effectiveness of vocabulary learning via mobile phones. The Turkish Online Journal of Educational Technology, 10(3), 203-214. 